\title{
Design of a Low-Cost Underwater LED Fishing Light Attractor
}

\author{
Geophrey Telemka, Mariana Mghamba, Amos Ntarisa* \\ Mkwawa University College of Education, Iringa, Tanzania \\ Email: *ntarisa@yahoo.com
}

How to cite this paper: Telemka, G., Mghamba, M. and Ntarisa, A. (2018) Design of a Low-Cost Underwater LED Fishing Light Attractor. Circuits and Systems, 9, 67-73.

https://doi.org/10.4236/cs.2018.94007

Received: March 23, 2018

Accepted: April 20, 2018

Published: April 23, 2018

Copyright $\odot 2018$ by authors and Scientific Research Publishing Inc. This work is licensed under the Creative Commons Attribution International License (CC BY 4.0).

http://creativecommons.org/licenses/by/4.0/

\begin{abstract}
Fishermen generally use light as a common way to attract fish in the fishing industry. This study aimed to design a model of an underwater fishing using Light Emitting Diode (LED) lamp which is less costful and suitable for fishermen of Tanzania. Most fishermen currently use kerosene based lamps like candela which consumes lots of energy leading to high cost in terms of money used to regenerate the energy. This running cost automatically rises up the price of fish in the market. Thus with the use of LED lamp the cost will be reduced. The findings from this study showed that the LED lamp consumes little amount of energy (energy saving) compared to candela lamp which consumes 6 liters of kerosene per 36 hours which is equivalent to three nights, while the LED lamp takes 7 batteries at once for 36 hours. The 6 liters of kerosene cost around 7 USD and that of 7 batteries cost is near 2 USD. The LED lamp can be accessed by only 15 USD the price which is nearly half the price of the candela lamp. The candela lamp in the market is sold around 31 USD. This shows that LED lamp is more efficient in terms of conserving energy and cost effective than candela lamp. It is recommended that fishermen in the fishing industry in Tanzania should employ the usage of underwater LED fishing lamps as they are energy efficient. This will help the fishermen of Tanzania to undertake the fishing activity at low cost which will result to the decrease of price of fish in the market. This shows that this LED lamp has high efficiency and effectiveness to be used by fishermen compared to traditional method used by majority of them.
\end{abstract}

\section{Keywords}

Underwater, Fishing Lamp, LED, Light Emitting Diode, Fishermen, Fishing Light, Attractor

\section{Introduction}

Fishermen use light to attract fish to form a large shoal using artificial light 
source at night or when the weather is cloudy [1] [2]. Therefore, fishing lamp is the most important equipment used in fishing activities. Examples of widely used fishing lamps include filament lamps, halogen tungsten lamps, metal halide lamps and candela lamps, all of them belonging to thermal light source. Fishing lamps can be categorized into two, that is, overwater fishing lamps and underwater fishing lamps [1] [3]. Overwater fishing lamps are always suspended near the water surface by hanging them on the rod which is tighten on the boat where they give out light to attract fish, for example candela lamps [4] [5]. On the other hand underwater fishing lamps are dipped into water for the same purpose, for example Light Emitting Diode (LED) lamps. It has been found that semiconductor lighting technology-LED has advantages of energy saving [2] [5] [6] [7]. Overwater fishing lamp is suspended near the water surface, and then half of the light is wasted, because the water surface is like the mirror which reflects (sends back) half of the light up in air. While with an underwater fishing lamp, you do not lose any light hence all the light from the lamp spreads underwater and attracts more fish [8] [9].

Most fishermen in Tanzania particularly are still using candela lamp to attract fish so that they can capture them using the nets they have. These candela lamps are expensive to run as they consume a lot of energy (kerosene fuel consumption in particular). Since fuel consumption is large, then expenditures (money) becomes very high in buying kerosene fuel (that its price is increasing everyday) to regenerate energy in those lamps. Thus, to solve these problems the research aimed to design underwater fishing lamp which is expected to be more efficient than candela lamps. The device will enable the fishermen to attract more fish which leads to more production. Also it is expected that the price of fish in the market to be reduced because the running cost of the device will be low compared to the running cost of candela lamp.

\section{Analysis and Design}

In order to design the LED underwater fishing lamp, the following material were required; Two green $\operatorname{LED}_{\mathrm{s}}(1.7 \mathrm{~V}-2 \mathrm{~V})$, A hollow glass beaker/test tube-housing, A resistor (50 $\Omega-100 \Omega$ ), Connecting wires-including the long one that will be used as a suspender of the lamp (approximately $5 \mathrm{~m}$ ), The cork/rubber stopper that fits in the tube, The key/switch, The source/battery $(6 \mathrm{~V}-12 \mathrm{~V})$, and The battery holder.

First, the two $\mathrm{LED}_{\mathrm{S}}$ were connected in series the correct way round that is, anode to cathode connection as shown in Figure 1.

$\mathrm{LED}_{\mathrm{S}}$ can be damaged by heat when soldering, but the risk is small unless you are very slow. No special precautions for soldering most $\mathrm{LED}_{\mathrm{S}}$. Second, connect such $\mathrm{LED}_{\mathrm{S}}$ in series with a resistor to limit the current to a safe value because if the $\mathrm{LED}_{\mathrm{S}}$ are directly connected to a battery or power supply they can be destroyed almost instantly since too much current will pass through and burn them out. Third, Connect the $\mathrm{LED}_{\mathrm{S}}$ \& resistor to the power supply/battery as shown in Figure 2. 


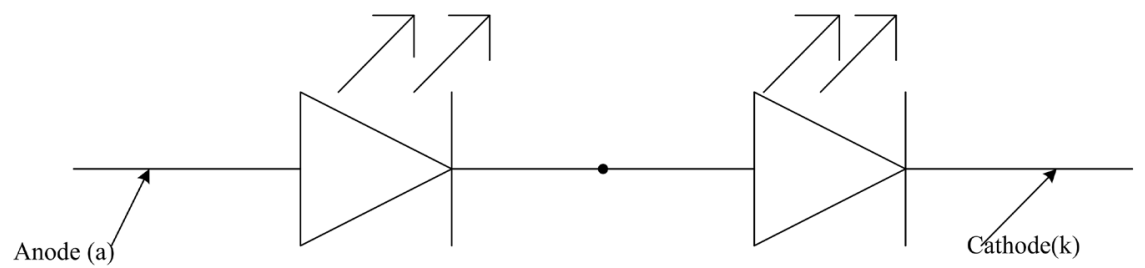

Figure $1 . \mathrm{LED}_{\mathrm{s}}$ in series connection.

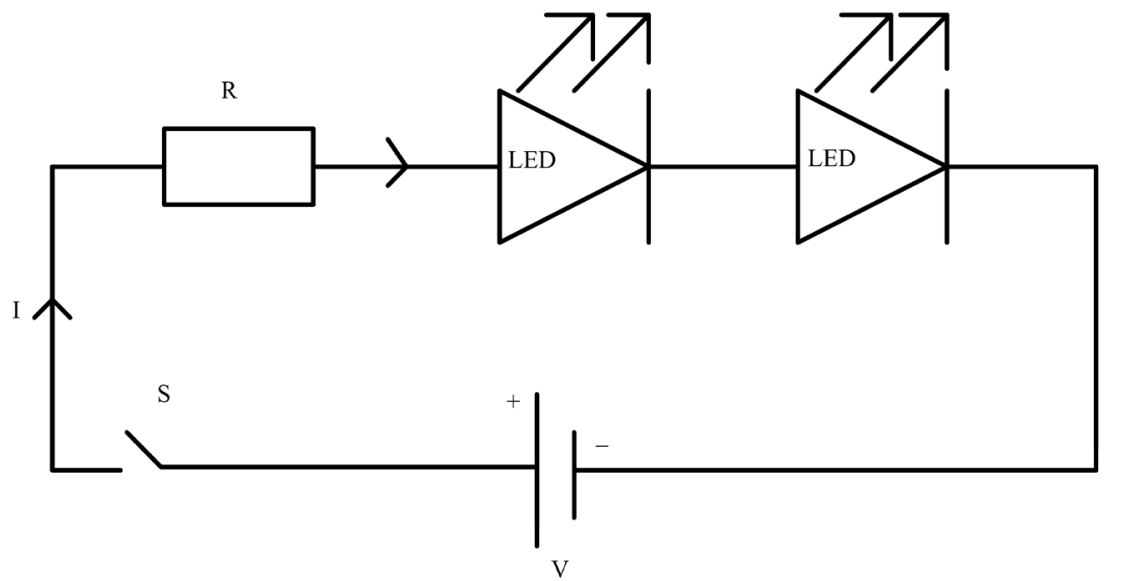

Figure 2. $\mathrm{LED}_{\mathrm{S}}$ and resistor connected to the power supply.

Fourth, Calculating $\mathrm{LED}_{\mathrm{S}}$ resistor value, to figure out which resistor to use, the following formula used;

$$
R=\left(V_{S}-V_{L}\right) / I .
$$

where: $V_{S}=$ power supply voltage, $V_{L}=$ sum of $L_{E D}$ voltage

$\left(V_{L}=V_{d 1}+V_{d 2}+\cdots\right)$ as shown in Figure 3, $I=$ LED current.

Fifth, drill a hole into the middle of the cork/rubber stopper that fits into the beaker/test tube. This hole is used to thread out the wires, for positive and negative terminals of the circuit which will be connected to the switch and battery. Then, place the $\mathrm{LED}_{\mathrm{S}}$ into the test tube, and then secure the cork/rubber stopper into the test tube top. Wrap the seam with black tape, and then wrap black tape securely around the wire and stopper to cover up the gaps in this hole. After completing all the steps, thus connect the two wires to their respective terminals-positive and negative of the battery to complete the circuit; the device is ready for use.

\section{Results and Discussion}

The testing of the LED lamp, it was dipped into the container of water to check the intensity of light produced. This is to check if the intensity of light will attract fish. The LED lamps were left on for 6 hours as we expect that the device will work during the night for those 6 hours. These 6 hours is the corresponding time which the candela lamp consumes one liter of kerosene. The target is to check the rate of energy consumption. Figure 4 shows the lamp before immersed in water while Figure 5 shows the lamp immersed in water. 


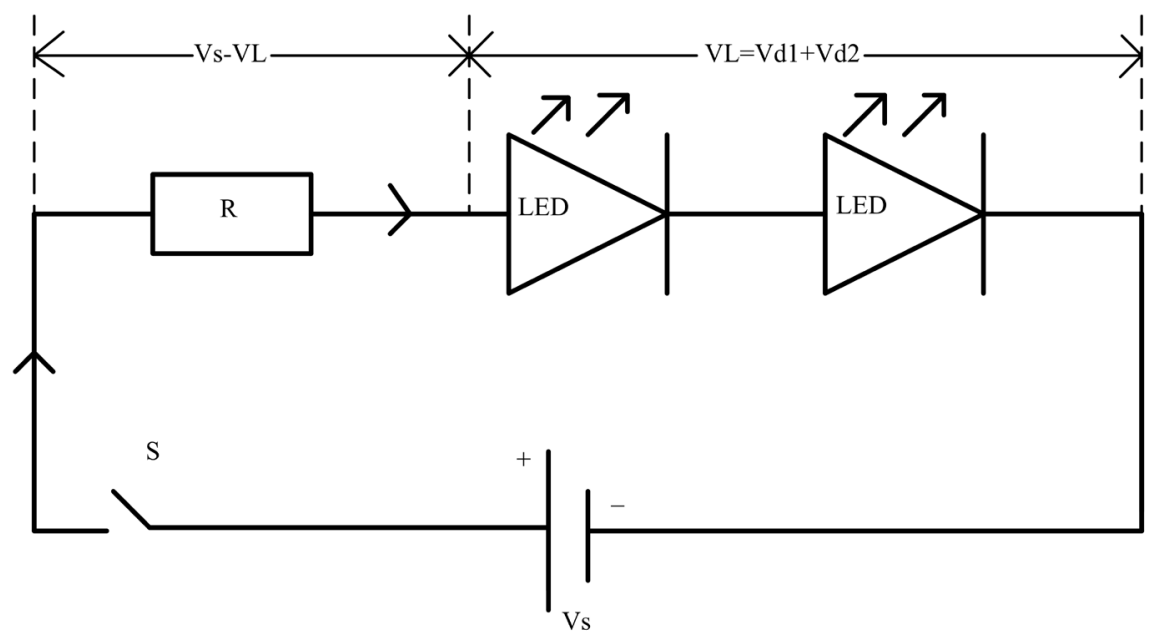

Figure 3. The complete circuit diagram.
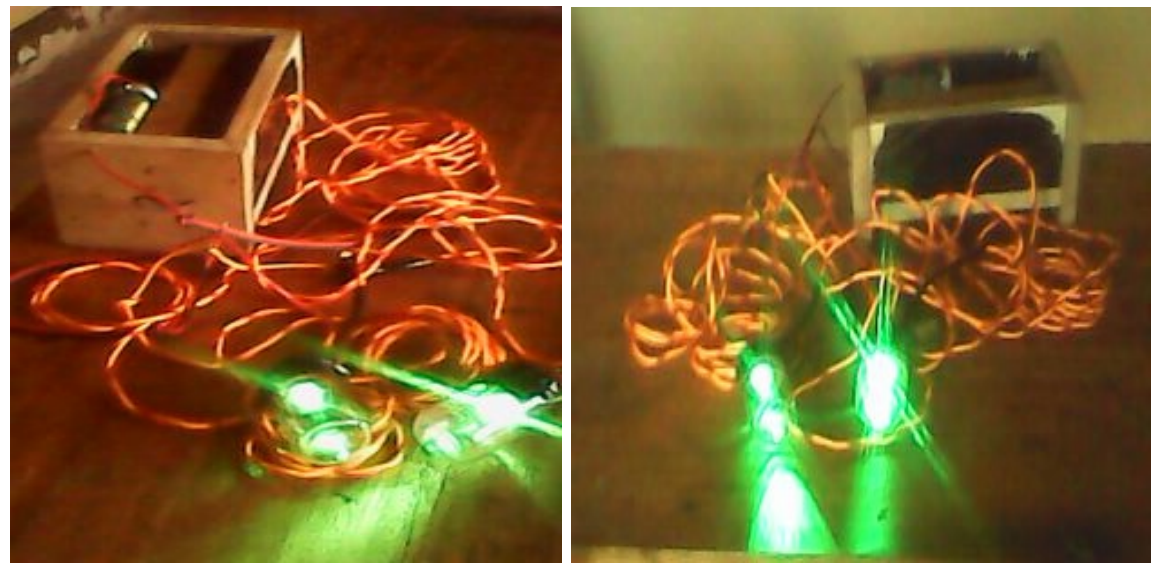

Figure 4. Showing underwater LED lamp before immersed in water.
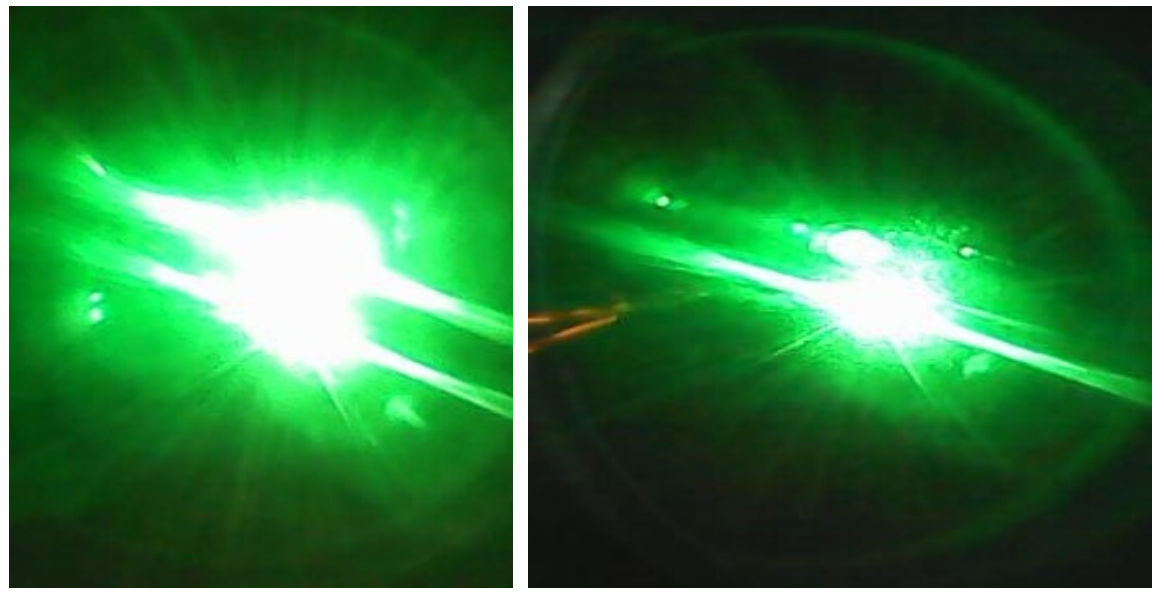

Figure 5. The LED lamp immersed in water (used in this study).

The following were observed when testing the LED lamp; the minimum voltage at which the LED lamp with two $\mathrm{LED}_{\mathrm{S}}$ connected in series will light is from $6 \mathrm{~V}$ to $12 \mathrm{~V}$ maximum, below $6 \mathrm{~V}$ the lamp cannot light. The LED lamp pro- 
duced a satisfactory amount of light which could reasonably attract fish. The 7 batteries managed to run the LED lamp for three nights consecutively. This shows that the voltage was decreasing very slowly as measured by the voltmeter which indicates that the LED lamp conserve the energy much than the candela lamp. The voltage drop was recorded after every two hours and the results are presented in Tables 1-3 and the graphs of voltage drop are presented in Figures 6-8.

Table 1. Results of voltage drop for day one (used in this project).

\begin{tabular}{cccccccc}
\hline Time (hours) & 0 & 2 & 4 & 6 & 8 & 10 & 12 \\
\hline Voltage (V) & 10.5 & 10.45 & 10.40 & 10.00 & 9.75 & 9.50 & 9.25 \\
\hline
\end{tabular}

\section{A GRAPH OF V AGAINST T}

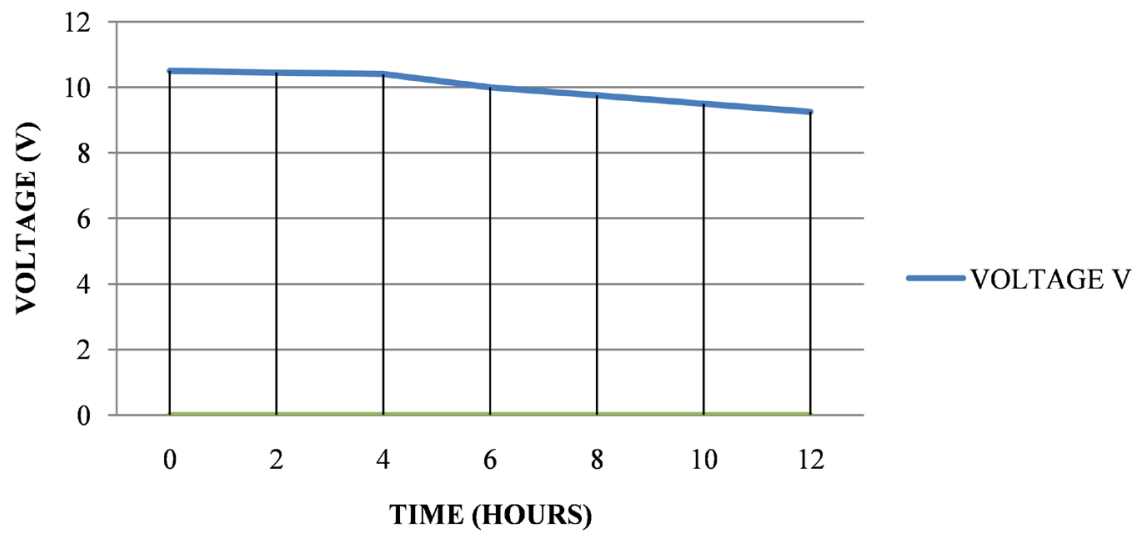

Figure 6. The graph of voltage drop for day one (used in this study).

Table 2. Results of voltage drop for day two.

\begin{tabular}{cccccccc}
\hline Time (hours) & 0 & 2 & 4 & 6 & 8 & 10 & 12 \\
\hline Voltage (V) & 9.25 & 9.00 & 8.75 & 8.50 & 8.25 & 8.00 & 7.75 \\
\hline
\end{tabular}

\section{A GRAPH OF V AGAINST T}

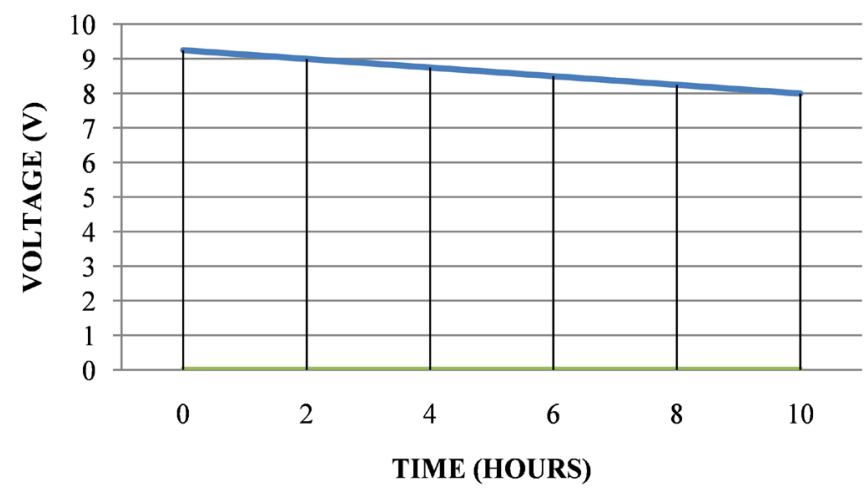

Figure 7. The graph of voltage drop for day two. 
Table 3. Results of voltage drop for day three.

\begin{tabular}{cccccccc}
\hline Time (hours) & 0 & 2 & 4 & 6 & 8 & 10 & 12 \\
\hline Voltage V & 7.75 & 7.50 & 7.25 & 7.00 & 6.75 & 6.50 & 6.25 \\
\hline
\end{tabular}

A GRAPH OF V AGAINST T

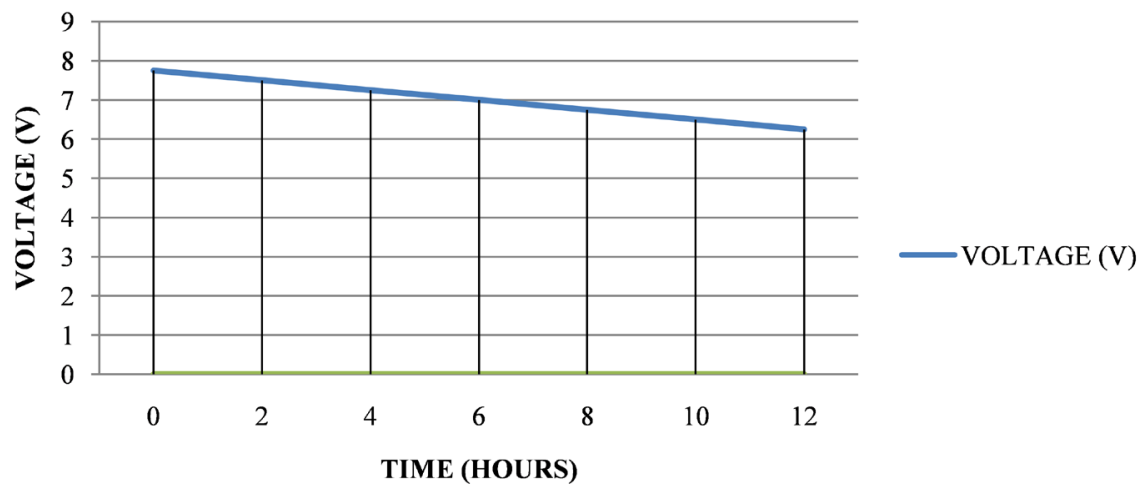

Figure 8. The graph of voltage drop for day three.

Table 4. The running cost of LED lamp and candela lamp for three days equivalent to 36 hours.

\begin{tabular}{cccc}
\hline Lamp & Energy Source & $\begin{array}{c}\text { Energy Consumption } \\
\text { for 3 Days }\end{array}$ & Cost US Dollar \\
\hline Candela & Kerosene & 6 liters & 7 \\
LED & Dry cells & 7 dry cells & 2 \\
\hline
\end{tabular}

From Tables 1-3, it was observed that the amount of light decreased as days goes on, for day one it was greater as batteries were new and for the two days the voltage was dropping very slowly but the LED lamp managed to produce the reasonable intensity of light for 36 hours. Thus it is assumed that the device can work properly when used in real context of fishing.

Also from Table 4, the LED lamp showed that it is cost effective as it used only 7 dry cells which cost around 2 US Dollar for 36 hours whereas the candela lamp costs 7 US Dollar to buy 6 liters of kerosene to run it for the same 36 hours.

From Table 4, it was observed that the running cost of the LED lamp is cheaper than that of candela. This is approximately four times the running cost of candela lamp. To determine how much energy is consumed by the candela lamp, the study talked to a fisherman from mtera dam and he gave the following details; the candela lamp consumes one liter of kerosene per 6 hours, that is from $1800 \mathrm{hrs}$ the time when they are entering the fishing field up to $0000 \mathrm{hrs}$, thus for the whole night of 12 hours the candela lamp consumes two liters of kerosene. The cost can also be reduced more by using rechargeable batteries.

\section{Conclusion}

The LED lamp is designed and the device is tested to check if it functions well. 
The device can be run at lower cost than candela lamp. The device is portable, affordable at half a price of candela lamp and is more efficient. During the construction of the LED lamp device it was very difficult to find the white LED $_{S}$ in our environment (Iringa municipal), that was why we decided to use the green $\mathrm{LED}_{\mathrm{S}}$ which are readily available and are functioning in the same way as the white $\mathrm{LED}_{S}$. It is advised to design underwater using white $\mathrm{LED}_{\mathrm{S}}$. This is due to the reason that light produced by white $\mathrm{LED}_{\mathrm{S}}$ is clearer than that of the colored ones. In this way more fish products will be obtained and the price of fish in the market will be reduced more. Also it is recommended that fishmen in the fishing industry employ the use of underwater LED fishing lamps so as to replace the kerosene based fuel lamps in Tanzania. This cost reveals itself in kerosene price which is increasing daily. The cost of operation can also be reduced by using rechargeable batteries.

\section{References}

[1] Guibault, G.G. (1990) Practical Fluorescence. 2nd Edition, Marcel Dekker Inc., New York.

[2] Li, T.H. and Jing, X. (2013) Research on LED Fishing Light. Research Journal of Applied Sciences, Engineering and Technology, 5, 4138-4141. https://doi.org/10.19026/rjaset.5.4639

[3] Isam, A., Hirosh, A., Masahiro, K. and Kazumasa, H. (1989) P-Type Conduction in Mg-Doped GaN Treated with Low-Energy Electron Beam Irradiation (LEEBI). Japanese Journal of Applied Physics, 28, L2112-L2114.

[4] Nakamura, S. and Senoh, M. (1994) Candela-Class High-Brightness InGaN/AlGaN Double-Heterostructure Blue-Light-Emitting Diodes. Applied Physics Letters, 64, 1687-1689.

[5] Ohno, Y. (2004) Color Rendering and Luminous Efficacy of White LED Spectra. National Institute of Standards and Technology, Gaithersburg, MD.

[6] Shen, S.C., Kuo, C.Y. and Fang, M.-C. (2013) Design and Analysis of an Underwater White LED Fish-Attracting Lamp and Its Light Propagation. International Journal of Advanced Robotic Systems, 10, 183. https://doi.org/10.5772/56126

[7] Tanabe, S., Fujita, S., Yoshihara, S., Sakamoto, A. and Yamamoto, S. (2005) YAG Glass-Ceramic Phosphor for White LED II: Luminescence Characteristics. Graduate School of Human and Environmental Studies, Kyoto University, Japan.

[8] Ben Yami, M. (1988) Attracting Fish with Light (Fao Training Series No. 14). Food and Agriculture Organization of the United Nations, Rome.

[9] Yoshizawa, T. (2009) Hand Book of Optical Metrology: Principles and Applications. CRC Press, Boca Raton. https://doi.org/10.1201/9781420019513 